\title{
Risk Management of COVID-19 by Universities in China
}

\author{
Chuanyi Wang ${ }^{1}\left(\mathbb{D}\right.$, Zhe Cheng ${ }^{1}$, Xiao-Guang Yue ${ }^{2} \mathbb{D}$ and Michael McAleer ${ }^{3,4,5,6,7,8, *(\mathbb{D})}$ \\ 1 Institute of Education, Tsinghua University, Beijing 100091, China; wcy1985@tsinghua.edu.cn (C.W.); \\ chengz19@mails.tsinghua.edu.cn (Z.C.) \\ 2 School of Sciences, European University Cyprus, 1516 Nicosia, Cyprus; x.yue@external.euc.ac.cy \\ 3 Department of Finance, College of Management, Asia University, Wufeng District, Taichung 41354, Taiwan \\ 4 Discipline of Business Analytics, University of Sydney Business School, Sydney, NSW 2006, Australia \\ 5 Econometric Institute, Erasmus School of Economics, Erasmus University Rotterdam, 3062 Rotterdam, \\ The Netherlands \\ 6 Department of Economic Analysis and ICAE, Complutense University of Madrid, 28040 Madrid, Spain \\ 7 Department of Mathematics and Statistics, University of Canterbury, Christchurch 8041, New Zealand \\ 8 Institute of Advanced Sciences, Yokohama National University, Kanagawa 240-8501, Japan \\ * Correspondence: michael.mcaleer@gmail.com
}

Received: 18 February 2020; Accepted: 18 February 2020; Published: 19 February 2020

\begin{abstract}
The rapid spread of new coronaviruses throughout China and the world in 2019-2020 has had a great impact on China's economic and social development. As the backbone of Chinese society, Chinese universities have made significant contributions to emergency risk management. Such contributions have been made primarily in the following areas: alumni resource collection, medical rescue and emergency management, mental health maintenance, control of staff mobility, and innovation in online education models. Through the support of these methods, Chinese universities have played a positive role in the prevention and control of the epidemic situation. However, they also face the problems of alumni's economic development difficulties, the risk of deadly infection to medical rescue teams and health workers, infection of teachers and students, and the unsatisfactory application of information technology in resolving the crisis. In response to these risks and emergency problems, we propose some corresponding solutions for public dissemination, including issues related to medical security, emergency research, professional assistance, positive communication, and hierarchical information-based teaching.
\end{abstract}

Keywords: COVID-19; Wuhan; Chinese universities; risk management; public safety; Information technology; online education

\section{Introduction}

In December 2019, the phenomenon of collective pneumonia appeared in the South China seafood market in Wuhan, Hubei Province, China (Huang et al. 2020). The National Health Commission sent experts to Wuhan to investigate. A novel coronavirus (hereafter COVID-19 for COronaVIrus Disease 19) was detected in the Laboratory of Virology, Chinese Center for Disease Control and Prevention on 7 January 2020 (The State Council of The People's Republic of China 2020). The number of patients with pneumonia virus has skyrocketed and has spread throughout China, and unintentionally exported internationally. On 23 January 2020, all Channels in Wuhan were temporarily closed (Yue et al. 2020). As of 15 February 2020, the number of confirmed patients was 68,500 (Sina News 2020). The daily updates suggest the confirmed global cases detected currently stand at 73,451, with 1875 deaths, as of 19 February 2020. These numbers are likely to have increased substantially well before this paper is published. 


\section{Quick Response from Chinese Universities}

Social services are an important function of universities (Wang and Zha 2018). Providing support for outbreak control is both a university function and a responsibility. Facing the new type of coronavirus, Chinese universities have responded reasonably quickly. Although the Chinese are looking forward to the most important festival of the year, the Spring Festival, universities have still been performing higher education functions, and playing their traditional role in terms of social services, scientific research and talent training functions.

\subsection{Make Use of Alumni Resources and Raise Medical Supplies}

At the beginning of the epidemic, universities across the country used alumni resources to immediately set up and open material support channels. Students and graduates at home and abroad have spontaneously organized and donated materials to the severely affected Hubei province. Huazhong University of Science and Technology Alumni Association from Germany and Australia collected and purchased materials that arrived fast in Wuhan (Sina Financial News 2020). The Overseas Alumni Association of Wuhan University also delivered materials from New York to Wuhan within $72 \mathrm{~h}$ (The Paper News 2020). They all have made important practical and supportive contributions.

\subsection{Gather Medical Experts for Emergency Research}

On the frontline of the epidemic, many medical schools (and hospitals) of universities across the country are assisting or specializing in treating local patients (China Education Daily 2019). At the critical stage of epidemic prevention and control, the top four of the Chinese medical community, Qilu Hospital of Shandong University, Xiangya Hospital of Central South University, Peking Union Medical College Hospital, and West China Hospital of Sichuan University, all arrived in Wuhan, the origin ground zero of the epidemic, to support medical work (Tencent News 2020).

The People's Hospital of Wuhan University and Wuhan Institute of Virology, Chinese Academy of Sciences, jointly discovered that the spread of the COVIC-19 pneumonia includes faeces and other contents (Sohu News 2020). South China Agricultural University and the People's Liberation Army Military Academy of the Military Medical Research Institute have found that the similarity between the strain isolated from a mammal that is threatened with extinction, the pangolin, has $99 \%$ similarity with COVID-19 (CCTV Net 2020).

The scientific research team of Shanghai Jiaotong University has provided strong technical support for the release of the first new type of coronavirus detection kit in China through the application of nanometer magnetic carriers developed over several years (ScienceNet News 2020). Tianjin University and Beijing Huaketai Biotechnology Co., Ltd. and other units have developed a new detection kit that has been able to perform seemingly accurate virus screening and detection in 15 minutes (Tianjin University 2020).

\subsection{Provide Psychological Assistance to Help Social Stability}

With the deepening of epidemic prevention and control, public roads are subject to traffic control, and residential communities are under closed management. In order to prevent and solve the psychological problems of citizens at home for indefinite extended periods, major universities have provided psychological counselling services.

Tsinghua University in Beijing combined with a number of institutions and units to launch an emergency public welfare project on "Combating Epidemics and Psychological Assistance" to provide online frontline medical workers and the public with psychological assistance and one-on-one psychological counselling (Tsinghua University 2020).

Shaanxi Normal University published the nation's first Mental Health Guidance Manual for the "Anti-epidemic War", which is published online and offline, to calm the citizens. Professors of some colleges and universities of physical education have demonstrated videos of home exercise programs 
to help citizens adjust their physical and mental health and improve their immunity (Shaanxi Normal University 2020).

\subsection{Controlling Personnel Flow and Innovative Teaching}

Student groups are one of the important components of China's inter-provincial mobility. In order to strengthen isolation and quarantine the channels of communication, many universities have decided to implement a delayed start to the academic year. At present, there are 33.66 million college students in China, of whom 8.83 million are inter-provincial students. During this period, colleges and universities have announced the postponement of school opening, which is helpful for epidemic control.

At the same time, in order to prevent delays in educational progress, under calls from the Ministry of Education of China, colleges and universities have implemented online education network platforms to help college teachers conduct online lectures through systematic training and technical support. Many leading universities have shown remarkable initiative in accepting their social responsibilities, opening teaching platforms to society without charge, sharing more than ten thousand high-quality course resources. High profile examples include the Peking University Lecture Network, Tsinghua University Online School, and Beijing Foreign Studies University Foreign Language Online Learning Platform, among others.

The Higher Education Bureau of Macau has provided online learning resources specifically for Macanese students studying in Taiwan, by helping them to improve their professional knowledge without leaving their homes, ensuring that their studies are not seriously affected. Some universities have also provided transfer services for Macanese students studying in Taiwan (Higher Education Bureau of Macau 2020).

\section{Challenges}

In this battle of epidemic prevention and control, Chinese universities have provided significant support and made remarkable achievements in epidemic control and social stability. The outbreak has set new requirements for sustainable risk management (Luo et al. 2020). For Chinese universities, these requirements have arisen primarily in the following areas.

\subsection{Medical Support Raises the Risk of Infecting Medical Staff}

For health and medical staff at the frontline of viral prevention and control, their life safety is still under constant challenge, such that the tension of related materials understandably makes the auxiliary staff at Chinese universities extremely nervous. Universities have undertaken important tasks for the cultivation of Chinese medical talents and high-level collaborative research. University medical personnel face the risk of infection, and even death, which is not conducive to the development of China's medical cause.

\subsection{Short-Term Research to Achieve Results Remains Untested}

Judging from the scientific research progress related to any possible cure of the COVID-19 epidemic, the current research results of universities and laboratories do not yet seem to have determined the source and transmission route of the virus. Moreover, virus vaccines are still under development, and related therapeutic drugs are still in the clinical experimental stage. As a basis of comparison, namely SARS in 2002-2003, effective SARS-specific drugs had not been discovered before the end of the first year. It remains to be seen whether the current research on a range of possible vaccines for COVID-19 will be successful.

\subsection{Quarantining of Student Groups Will Have a Devastating Impact on the Campus Economy}

Student group consumption is an important means for stimulating economic growth. Chinese student group consumption has played a huge role in driving the catering, entertainment, shopping, 
and technology industries. However, a period of a few months of isolation will lead to severe and devastating economic impacts on student campus life. The cost of personnel and the cost of unused fixed assets make it impossible for such enterprises to survive, so many shops and individuals will inevitably face bankruptcy.

\subsection{Problem-Applications of Information Technology in Teaching}

Online lectures based on a wide range of information technology equipment raised serious challenges. Teachers who are used to teaching live classes will need to engage in novel methods to achieve effective teaching outcomes, which may affect the quality of tertiary education. Students in remote and rural areas may not have the network capacity, thereby leading to a loss in educational opportunities. In addition, teachers who provide classes on taped broadcast network may face problems of copyright in disseminating the information.

\section{Suggestions}

What is particularly alarming is that an end of the COVID-19 epidemic prevention and control battle is nowhere in sight. Universities need to continue to overcome difficulties in the ongoing battle, from students to teachers, and medical personnel from outside the discipline, with researchers needing to redouble their sustained efforts to discover an effective vaccine.

\subsection{Protect the Safety of Health Care Workers}

At present, whether it is in health care or university teaching, essential medical resources are in short supply. Colleges and universities should actively mobilize human and material resources to ensure the safety of the public, and the work of medical security personnel, to maintain and consolidate the initial achievements of epidemic prevention and control.

\subsection{Emergency Research and Sustainable Collaborative Research Network}

University researchers should continue in-depth research on COVID-19. University research institutions should collaborate actively with each other, and strive to achieve positive outcomes in the short term. They should seek prevention and control of the epidemic, investigate long-term issues about possible mutation, share the latest research progress, and establish collaborative research and technological networks to guarantee sustainable COVID-19 research. As graduate education provides important support for national scientific and technological innovation (Wang et al. 2019), special attention must be given to the cultivation of this emerging research force, which is not only a witness to the present epidemic, but also a guardian of future generations against possible future coronavirus epidemics.

\subsection{Professional Advantage and Social Responsibility}

Researchers outside the health and medical fields should be use their professional knowledge in their areas of expertise. They should also accept a responsible degree of academic freedom, maintain professional integrity, contribute to the understanding and explanation of the epidemic, support prevention and control, use the Internet actively and professionally, distribute useful and helpful information about the epidemic, retain a clear mind, and identify network dissemination of information to guide social rationality.

\subsection{Students in Communication Channels Can Help Social Stability}

In order to play a guiding role, college students can assist community safety, control the transfer of scientific knowledge, appease the emotions of people in society, respond to serious rumors while rejecting the more colorful ones, dealing with panic, and establishing confidence in the community to overcome the epidemic. 


\subsection{Implementation of Information-Based Teaching Using Different Curriculum Characteristics}

Different courses have different characteristics, and teaching innovation must be flexible. For knowledge-based courses, the advantages of information technology can lead to network teaching in order to help college teachers apply information technology. For operational and practical courses, research and discussion courses, and physical education courses, the respective curricula can be modified and updated after vaccines have been developed for the COVID-19 epidemic.

Author Contributions: Conceptualization, C.W. and Z.C.; writing-original draft preparation, C.W. and Z.C.; writing-review and editing, C.W., X.-G.Y. and M.M.; supervision, M.M. All authors have read and agreed to the published version of the manuscript.

Acknowledgments: The fourth author wishes to acknowledge the financial support of the Australian Research Council and the Ministry of Science and Technology (MOST), Taiwan.

Conflicts of Interest: The authors declare no conflict of interest.

\section{References}

CCTV Net. 2020. South China Agricultural University: Pangolin-Carrying Strains Bear 99\% Similarity to Novel Coronavirus. Available online: http://tv.cctv.com/2020/02/08/VIDEpmeVt0k8FgfRcty7yp8S200208.shtml (accessed on 11 February 2020).

China Education Daily. 2019. Tribute to the Most Beautiful Retrograde! National University Medical Staff Helps Hubei | Special Attention. Available online: https://mp.weixin.qq.com/s/b2hYuSzBabppHq_XfK4hYw (accessed on 11 February 2020).

Higher Education Bureau of Macau. 2020. Australian University Opens Online Resources to Help Students Study in Taiwan and Macau at Ease. Available online: https://news.gov.mo/detail/zh-hant/N20BLbkkI1?0\&from= timeline (accessed on 11 February 2020).

Huang, Chaolin, Yeming Wang, Xingwang Li, Lili Ren, Jianping Zhao, Yi Hu, Li Zhang, Guohui Fan, Jiuyang Xu, Xiaoying Gu, and et al. 2020. Clinical features of patients infected with 2019 novel coronavirus in Wuhan, China. The Lancet 395: 497-506. [CrossRef]

Luo, Yu-Meng, Wei Liu, Xiao-Guang Yue, and Marc A. Rosen. 2020. Sustainable Emergency Management Based on Intelligent Information Processing. Sustainability 12: 1081. [CrossRef]

ScienceNet News. 2020. Shanghai Jiaotong University Launches First Novel Coronavirus Pneumonia Project. Available online: http://news.sciencenet.cn/sbhtmlnews/2020/2/353226.shtm?id=353226 (accessed on 11 February 2020).

Shaanxi Normal University. 2020. he First Mental Health Guidance Manual of the "War on Resistance to Epidemic" Was Formally Published by Our Publishing House. Available online: http://news.snnu.edu.cn/info/1012/ 22155.htm (accessed on 11 February 2020).

Sina Financial News. 2020. Guarding the "Fight" of the "Native Family": Huake Alumni Helped the Hubei to Fight the Epidemic, and Supplies Were Sent Directly to the Front-Line Departments. Available online: http://finance.sina.com.cn/wm/2020-02-08/doc-iimxyqvz1336454.shtml (accessed on 11 February 2020).

Sina News. 2020. A Total of 68,500 Newly Diagnosed Cases of New Coronary Pneumonia Nationwide. Available online: http://news.sina.com.cn/o/2020-02-16/doc-iimxxstf1795268.shtml (accessed on 16 February 2020).

Sohu News. 2020. New Discovery! Fecal-Oral Transmission of New Coronary Pneumonia. Available online: https://www.sohu.com/a/370157442_100013535 (accessed on 11 February 2020).

Tencent News. 2020. The "Four Great Heavenly Kings" of China Medical Cares Were Dispatched, and 18,000 Medical Elites Entered Hubei, and They Must Win. Available online: https://new.qq.com/omn/20200212/ 20200212A060AE00.html (accessed on 11 February 2020).

The Paper News. 2020. Speed of Life and Death | From New York to Wuhan, a 72-Hour Aid War "Outbreak". Available online: https://www.thepaper.cn/newsDetail_forward_5742184 (accessed on 11 February 2020).

The State Council of The People's Republic of China. 2020. Li Keqiang Went to China CDC to Inspect the Scientific Research of Novel CORONAVIRUS infection Pneumonia Prevention and Control. Available online: http://www.gov.cn/guowuyuan/2020-01/30/content_5473244.htm (accessed on 11 February 2020). 
Tianjin University. 2020. Tianda Team and Enterprise Jointly Develop New Kit for Rapid Detection of Novel Coronavirus in 15 Minutes. Available online: http://www.tju.edu.cn/info/1026/2664.htm (accessed on 11 February 2020).

Tsinghua University. 2020. Department of Psychology, Tsinghua University in action: “Combating Epidemics, Psychological Assistance" Emergency Public Welfare Project to Help Fight Epidemic. Available online: http://news.tsinghua.edu.cn/publish/thunews/10303/2020/20200202095132036222403/ 20200202095132036222403_html (accessed on 11 February 2020).

Wang, Chuanyi, and Qiang Zha. 2018. Measuring systemic diversity of Chinese universities: A clustering-method approach. Quality \& Quantity 52: 1331-47.

Wang, Chuanyi, Jiale Yang, Zhe Cheng, and Chaoqun Ni. 2019. Postgraduate Education of Board Members and R\&D Investment-Evidence from China. Sustainability 11: 6524.

Yue, Xiao-Guang, Xue-Feng Shao, Rita Yi Man Li, M. James C. Crabbe, Lili Mi, Siyan Hu, Julien S. Baker, and Gang Liang. 2020. Risk Management Analysis for Novel Coronavirus in Wuhan, China. Journal of Risk Financial Management 13: 22. [CrossRef]

(C) 2020 by the authors. Licensee MDPI, Basel, Switzerland. This article is an open access article distributed under the terms and conditions of the Creative Commons Attribution (CC BY) license (http://creativecommons.org/licenses/by/4.0/). 